\title{
Failure analysis and numerical simulation of slab carrying clamps
}

\author{
Branislav Đorđević, Simon Sedmak \\ Innovation Center of Faculty of Mechanical Engineering, University of Belgrade, 11120 Belgrade, Serbia \\ brdjordjevi@@mas.bg.ac.rs,bttps://orcid.org/0000-0001-8595-6930 \\ simon.sedmak@yahoo.com, bttps:/ /orcid.org/0000-0002-2674-541X
}

\author{
Drakče Tanasković, Marko Gajin \\ HBIS Group Serbia Iron \& Steel ltd., 11300 Smederevo, Serbia \\ drakcetanaskovi@@gmail.com
}

\section{Filip Vučetić}

Innovation Center of Faculty of Mechanical Engineering, University of Belgrade, 11120 Belgrade, Serbia fvuceti@@mas.bg.ac.rs

\begin{abstract}
The goal of this study was to determine the reasons for failure of slab carrying clamps which had occurred in one of the clamp support levers. Detailed fractography analysis revealed that there was a welded joint at the location where failure occurred, which was not expected, since the second lever was not welded. Once the presence of the welded joint was confirmed by hardness measuring and the analysis of chemical composition, attempts were made to determine which materials were used for the welding, in order to obtain a more detailed insight into the nature of the failure. The first step of this extensive analysis involved the development of a simple, approximated numerical model, with the goal of determining the location of stress concentration in the support lever, so that it could be compared to the real failure location. Further investigations will involve more complex models, including the ones that will simulate crack growth, once its location is numerically verified.
\end{abstract}

KEYWORDS. Failure; FEM analysis; Simulation; Welding influence; Fractography.

\section{OPEN ACCESS}

Citation: Đorđević, B., Sedmak, S., Tanasković, D., Gajin, M., Vučetić, F., Failure analysis and numerical simulation of slab carrying clamps, Frattura ed Integrità Strutturale, 55 (2021) 336-344.

Received: 04.12 .2020

Accepted: 25.12 .2020

Published: 01.01.2021

Copyright: (C) 2021 This is an open access article under the terms of the CC-BY 4.0, which permits unrestricted use, distribution, and reproduction in any medium, provided the original author and source are credited.

\section{INTRODUCTION}

nalytical calculations used for remaining life assessment, strength and load of machine elements provide the basis for checking the reliability of structures and elements under their corresponding working conditions. Scientific fields such as strength of materials and mechanics represent the basic disciplines which are used for this purpose, 
even today, often combined with real experience. Relations resulting from these disciplines were included in standards and are typically used in basic calculations related to equipment used for various purposes, subjected to different types of load. This approach is often not sufficient when it comes to analyzing of failure causes, and requires the aid of other scientific discipline and approaches, such as fracture mechanics and finite element methods (FEM).

This combination of analytical and numerical calculation is widely used in solving of certain engineering problems, wherein the assumptions and approximations adopted for the analytical calculations are used as input data for the FEM simulation. These simulations can be based on approximations resulting from strength of materials and statics principles [1-4], typically by their combined use. In addition, the combination of fracture mechanics and FEM principles is used for determining of the remaining life of structures, utilising experimental fracture mechanics data as the basis for the numerical simulation, as can be seen in the works of Milovanović et al [5] and Jeremić et al [6], both of which refer to hydro power plant equipment integrity (turbine in the former and a penstock in the latter case). In both cases, analytical and numerical analyses provided a solid basis for structural integrity of pipelines and other equipment via finite element method application. This combination is widespread in other literature as well, especially in case studies involving the investigation of failure causes, damage effects and integrity assessment, for a wide variety of structures [7-10]. More often than not, even all of this is insufficient, and other methods may need to be included, such as risk analysis [11, 12].

Each of the previously described approaches and analysis methods is often not sufficient, even with all assumptions and including of other disciplines, in terms of understanding of engineering problems, especially when it comes to structural failure analysis. The cause of this can sometimes lie in the simple facts, like not knowing the properties of the broken equipment, the ways in which it was manufactured, manufacturing process etc. All afore mentioned in previous sentence can be caused by age, or loss of certain technical documentation due to unexpected circumstances, human negligence, etc. Such circumstances impose the need for some form of inspection of the fractured surface, or even a thorough analysis of the whole structure or equipment, along with the need to take account all aspects which could affect and lead to equipment failure. Insufficient knowledge of the state of materials often requires a chemical and/or microstructural analysis of the fractured surface in order to gain better insight into the nature of the damage that had occurred [13-15]. If welding is included in this problem, along with its various technological, metallurgical and geometry, related problems become additionally complicated, especially when welding technology parameters are unknown (including the filler material characteristics, amperage, voltage etc.), or when it is not known if there was any welding to begin with. One such study, by Dzindo et al [16], which required the use extended finite element method (XFEM) for the purpose of simulating fatigue crack growth in a welded joint. It should be taken into account that insufficient amount of relevant information for the analysis can result in wrong conclusions taking the whole study in a wrong direction.

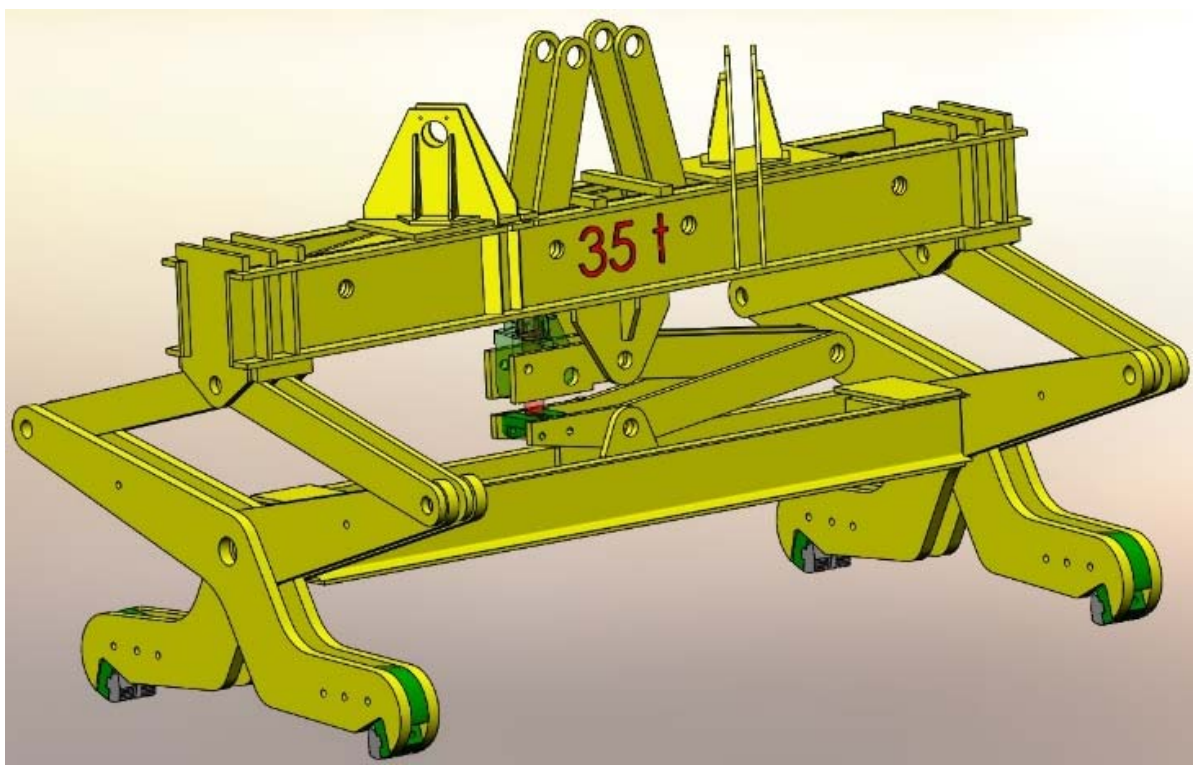

(a)

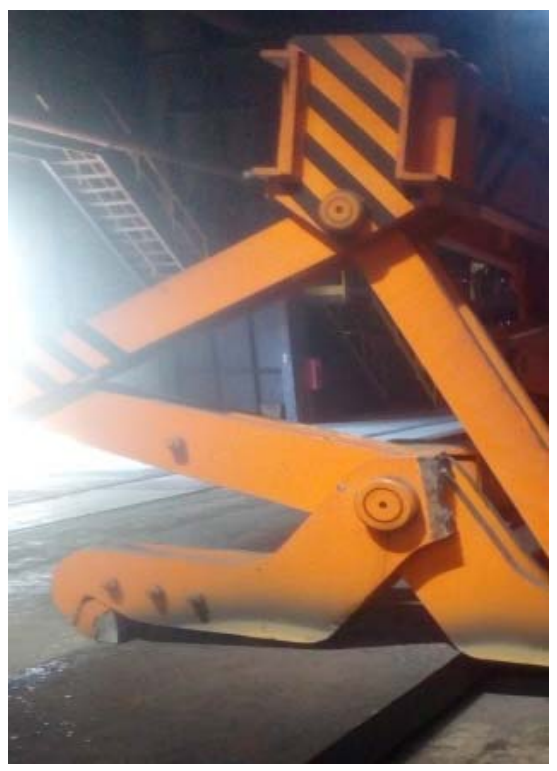

(b)

Figure 1: a) 3D model of the slab carrying clamps; b) One of the clamp levers where the failure occurred. 
This paper presents the analysis of slab carrying clamps failure, in the part of the clamp used for transporting slabs through the steel mill, wherein these slabs are used for further manufacturing of sheets in the hot-rolling facility. Clamps are exposed to static loads during their work life. In order to determine the reasons behind this failure, analytical and numerical calculations (using FEM) were performed, wherein numerical simulations were performed using ABAQUS software. Additionally, visual inspection of the entire equipment was performed, along with the chemical analysis of the fractured surface, which will be presented here in detail. Fig. 1a shows the 3D model of the clamps, whereas Fig. 1b shows the appearance of the broken support lever, i.e. the location of the failure. An additional complication arose due to the fact that the visual testing revealed a welded joint in one of the support levers, which resulted in the need for additional analyses, including the determining of the chemical composition of the fracture surface and discovering the reason why fracture had occurred. Based on the aforementioned figure, i.e. figure of lever fracture, it can be observed that the influence of welding was noticeable, but despite of that the following questions arose: why did failure occur and why was it not located in the central hole of the support lever?

\section{MACRO-FRACTOGRAPHY OF BROKEN LEVER SURFACE}

A s can be seen in the above figure, one pair of clamps, with a carrying capacity of $35 t$ consists of two levers. Fracture occurred in both of these levers, due to exploitation conditions, in service, which resulted in loads far exceeding the expected, i.e. calculated values. The second lever most likely failed after the first one broke, as it could not carry the full load on its own. On the Fig. 2 are presented fracture surfaces of the levers after performed visual inspection. This inspection also revealed that one of the lever was actually welded. This was initially assumed based on the fracture surface appearance, due to the presence of fusion lines. Figs. $2 \mathrm{a}$ and $2 \mathrm{~b}$ show the fracture surface of the welded lever, whereas Fig. $2 \mathrm{c}$ shows the fracture surface of non-welded lever. Differences in these surfaces of the two levers can be easily observed. In order to verify the above assumption that one of the levers was welded, hardness testing was performed on both levers, in the fracture location. This measuring was performed using adequately calibrated equipment, and is given in HB units of hardness. Fig. 3 a shows the measuring points on the lever which was welded. It can be seen that the region in the vicinity of the fracture surface has higher hardness $(236 \mathrm{HB})$, compared to the region further away (191 HB), which indicates that this was the heat affected zone of the weld. Fig. $3 \mathrm{~b}$ shows the measuring point in the lever which was not welded, also located in the vicinity of the fracture surface. No significant differences in hardness values were observed in this case, suggesting a much more homogeneous material, i.e. that there was no welded joint in this lever. Magnetic flux method of the NDT examination revealed no other cracks in the vicinity of fracture surfaces of both broken levers.

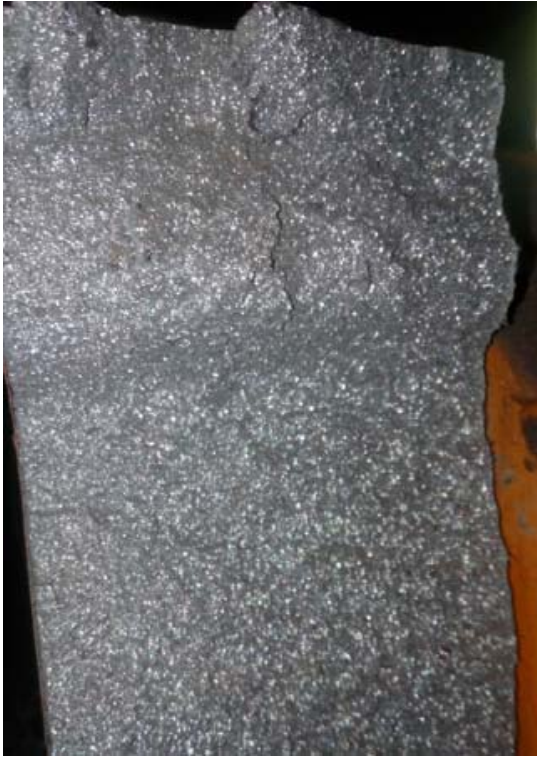

a)

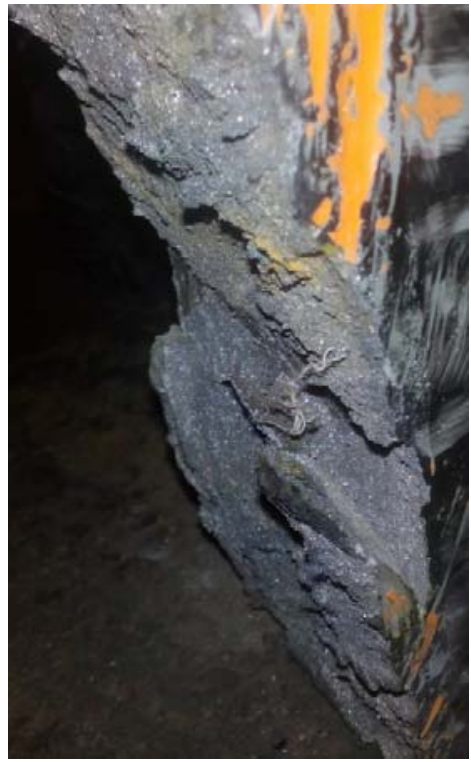

b)

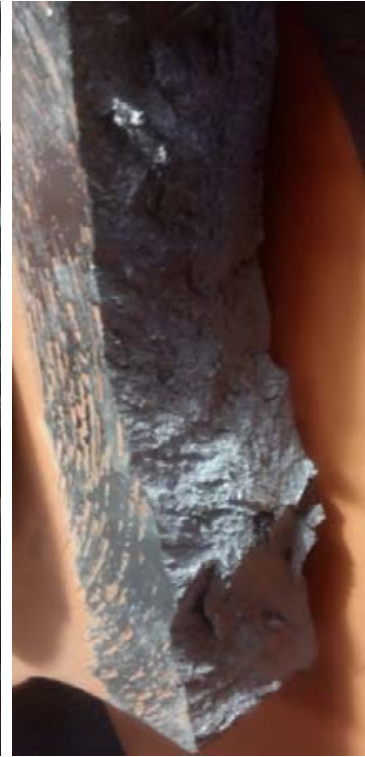

c)

Figure 2: a) Appearance of fracture surfaces of the welded lever; c) fracture surface of the non-welded lever. 


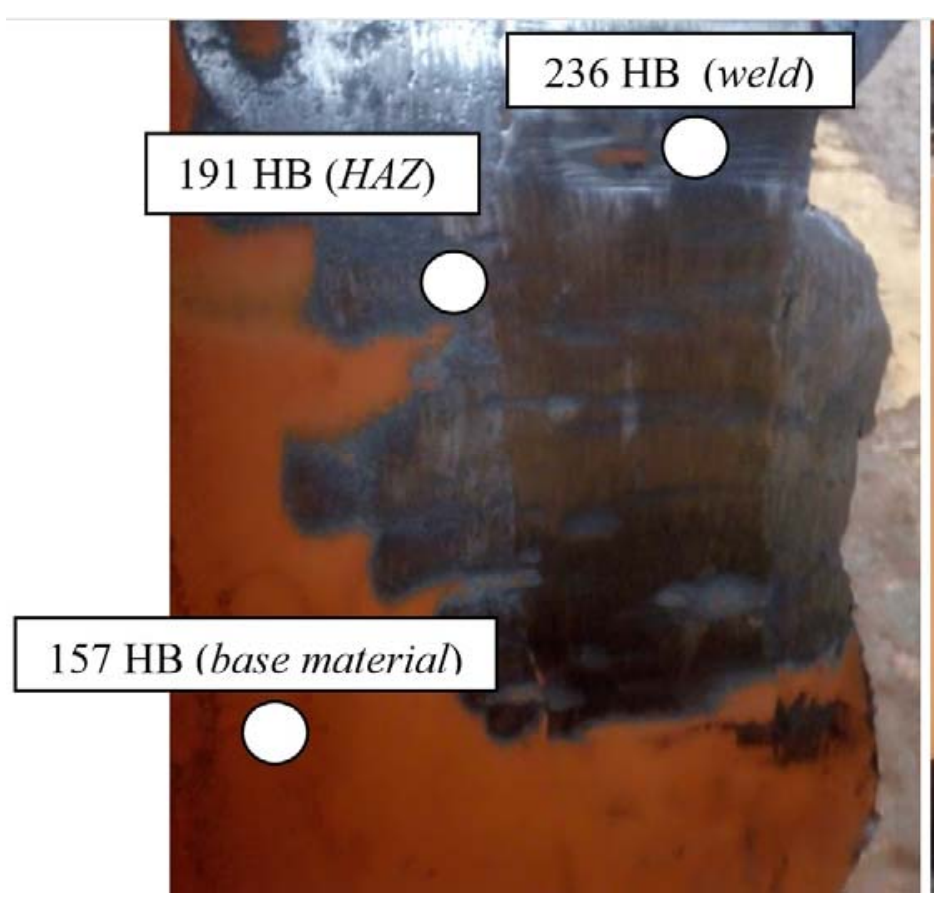

a)

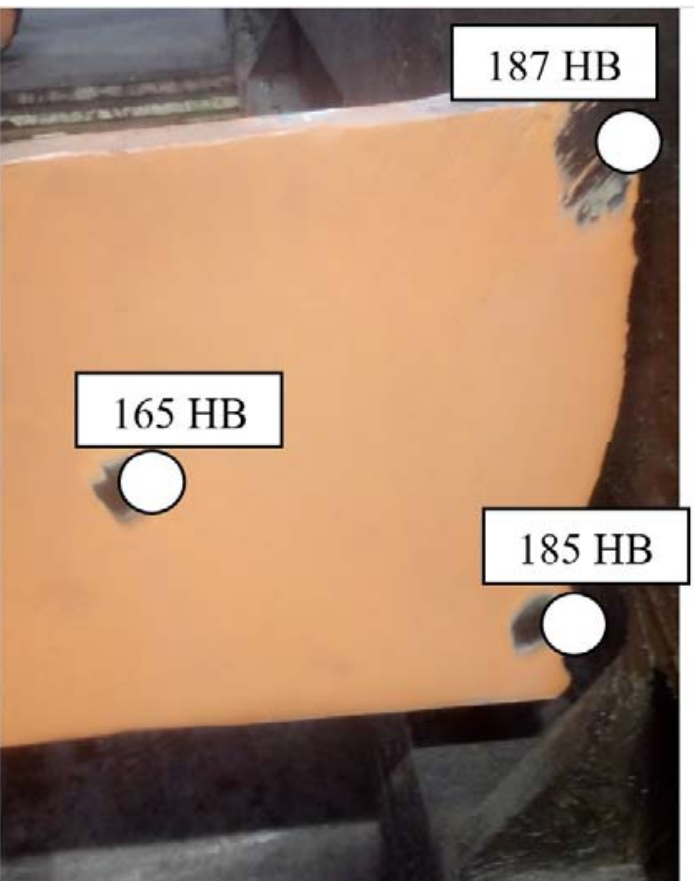

b)

Figure 3: a) Hardness values and measuring locations on the welded lever; b) Hardness values and measuring location on the non-welded lever.

\begin{tabular}{|c|c|c|c|c|c|c|c|c|c|c|c|c|}
\hline Element $[\%]$ & $\mathrm{C}$ & $\mathrm{Si}$ & $\mathrm{Mn}$ & $\mathrm{P}$ & S & $\mathrm{Cr}$ & $\mathrm{Ni}$ & $\mathrm{Cu}$ & $\mathrm{Al}$ & Mo & & $\mathrm{Ti}$ \\
\hline $\begin{array}{l}\text { Fracture } \\
\text { surface } \\
\text { (weld) }\end{array}$ & 0.234 & 1.540 & 3.451 & 0.023 & 0.010 & 19.28 & 8.685 & 0.143 & 0.033 & 0.3172 & & 0.0582 \\
\hline $\begin{array}{l}\text { Base } \\
\text { material }\end{array}$ & 0.2473 & 0.252 & 0.641 & 0.003 & 0.0072 & 0.0939 & 0.1148 & 0.249 & 0.034 & 0.0186 & & 0.002 \\
\hline Element $[\%]$ & As & V & $\mathrm{Nb}$ & Sn & W & $\mathrm{Sb}$ & $\mathrm{Ta}$ & $\mathrm{Co}$ & $\mathrm{N}$ & $\mathrm{Ca}$ & B & $\mathrm{Pb}$ \\
\hline $\begin{array}{l}\text { Fracture } \\
\text { surface } \\
\text { (weld) }\end{array}$ & 0.0059 & 0.1197 & 0.0303 & 0.0174 & 0.0019 & / & / & 0.0477 & / & 0 & 0 & 0 \\
\hline $\begin{array}{l}\text { Base } \\
\text { material }\end{array}$ & 0.009 & 0.003 & 0.001 & 0.011 & 0.0103 & 0.003 & 0.003 & 0.0184 & 0.01 & 0 & 0 & 0 \\
\hline
\end{tabular}

Table 1: Chemical composition of welded lever and the base material.

\section{CHEMICAL COMPOSITION ANALYSIS}

$\mathrm{T}$ he fact that one of the slab carrying clamp support levers was welded unknown until the failure had occurred. It should be pointed out that this equipment was in exploitation for over 20 years, and that the original documentation had no information about one lever being welded. It was known that the base material for the levers was S355 J2 G3, which is a non-alloy structural steel, with a yield strength is $350 \mathrm{MPa}$, while its tensile strength is in rage of 490-630 $\mathrm{MPa}$ [17], which depends on sheet thickness. On the other hand, characteristics and mechanical properties of the electrode, i.e. filler material, used for welding were unknown, as well as the welding parameters. Chemical analysis was performed in order to determine which type of filler material was used for welding of the lever, as well as to determine the state of the base material. This analysis was performed using optical emission spectrometry. Chemical composition of the fracture surface of the welded joint and the base material is shown in Tab. 1. Based on the chemical composition, mainly the chrome, nickel and manganese content, it can be concluded that the filler material used was similar to the high-alloyed austenitic type of electrode from series Inox 18/8, manufactured by Jesenice [18]. These types of electrodes are obviously not the electrodes 
that should be used for welding of low-alloyed structural steels, although their mechanical properties are similar and slightly better compared to the base metal.

\section{FEM ANALYSIS}

\section{Analytical calculation}

7 he stresses as well as loading in the lever pair were determined by using analytical calculations based on relations from scientific disciplines such as strength of materials and statics [19-21]. The calculation given here only applies to a relatively uniform load, i.e. the load which is equally distributed between the two clamps. Certain approximations were necessary for the sake of calculation, which included representing of the levers as simple beams and adopting of point A as the clamp support (Fig. 4). Fig. 4a represents the clamp lever loading scheme. Force $Q$ is the maximum working load of the clamps and is equal to $35 \mathrm{t}$ (converted to $343.5 \mathrm{kN}$ ). Force $\mathrm{G}_{\mathrm{x}}{ }^{*}$ represents the weight of the clamps and is equal to $10.5 \mathrm{t}$, whereas $\mathrm{F}_{\mathrm{k}}$ represents the sum of these two forces. Lever dimensions are given in centimeters.

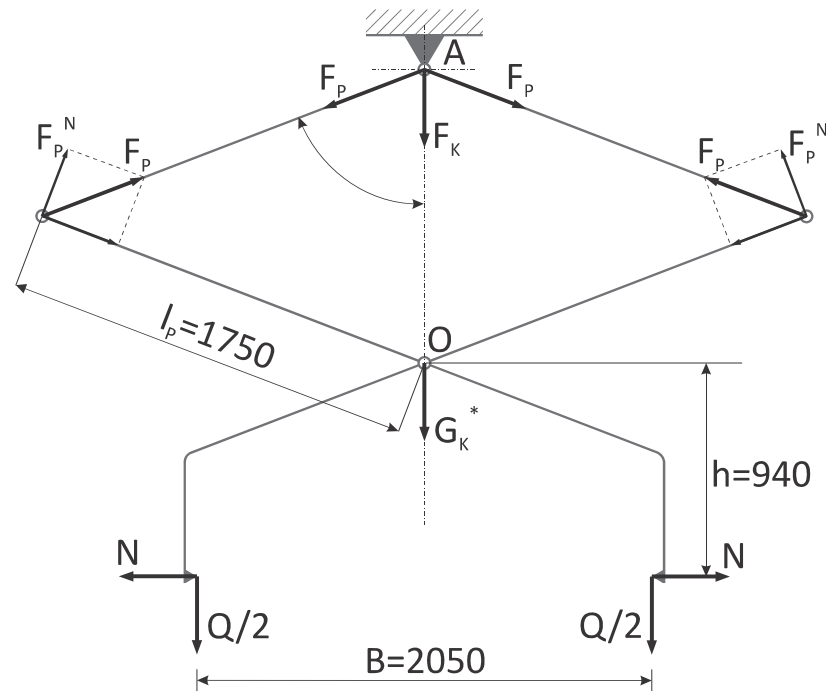

a)

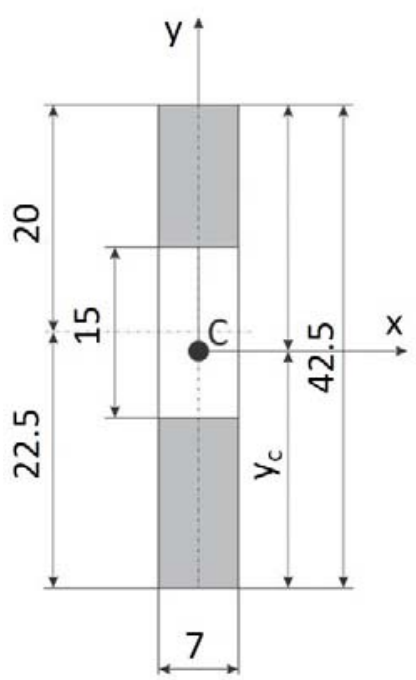

b)

Figure 4: a) Loading scheme of the levers, with their dimensions; b) lever cross section at the support O location and its dimensions.

By decomposing the forces along the directions of the levers and their normal components, and by using the well-known statics relation given by (1), the moment for point $\mathrm{O}$ is obtained, i.e. for the circular opening approximated with it. This moment equals $72688 \mathrm{kNcm}$. Since this moment is transferred onto four levers, the moment for each levers is equal to $18172 \mathrm{kNcm}$ according to (2).

$$
\begin{aligned}
& M_{O}=F_{P}^{N} \cdot l_{p} \\
& M_{O}^{1}=\frac{M_{O}}{4}
\end{aligned}
$$

Fig. $4 \mathrm{~b}$ shows the cross-section of one of the levers at the support, along with the dimensions. Basic concepts of strength of materials were used to determine the cross-section centre mass, moment of inertia and the elastic section modulus in the "upper" and the "lower" zone (denoted as U and L), and the stresses in both these zones were obtained for a lever which was subjected to compression in the "upper" and tension in the "lower" zone, as shown by relations (3) and (4). Values of stresses obtained by these calculations were as follows: $-93 \mathrm{MPa}$ for the upper zone (negative due to the fact these were compressive stresses), and 88.4 MPa in the lower zone of the cross section. These values were below the allowed stress for the lever, which was $230 \mathrm{MPa}$. This value was determined based on the yield stress of the base material and the safety factors which are adopted in these cases (and are usually around 1.5). 


$$
\begin{gathered}
\sigma_{X}^{U}=-\frac{M_{O}^{1}}{W_{X}^{U}} \\
\sigma_{X}^{L}=\frac{M_{O}^{1}}{W_{X}^{L}}
\end{gathered}
$$

In the case of extremely non-uniform load, to be accurate, when only one pair of clamps is subjected to the full load, maximum values for the "upper" and "lower" zones are obtained -186 MPa and 176.8 MPa, respectively. Even though these values are, as expected, two times higher than the stresses obtained in the case of uniform load on both pair of clamps, and they are still below the allowed stress levels. These remarks and afore obtained load level leave the space for numerical simulation and FEM analysis, because analytical calculation did not give the answer of reason for fracture occurrence.

Analytical calculations presented in this section provided the input data (in terms of loads) and the information necessary (allowed stresses and actual stresses in the levers) for numerical simulation, which was performed in ABAQUS Dassault Systèmes software package. Numerical part of the analysis will be presented in the following section.

\section{Simulation in $A B A Q U S$}

Numerical simulation in this research was focused on one of the levers, for the purpose of determining the stresses that would occur in it, and whether the critical location (where highest tensile stresses were observed) would correspond to the actual fracture location, without taking into account the material heterogeneity. This was done in order to see if the initial assumptions about the model were correct, and to determine the location of crack initiation in the future, improved models. For the reason of initial model simplicity, certain approximations were made to the model - only the fractured lever itself was modelled, and its connection with the upper lever which is supported in point A from the Fig. 4 was replaced with the corresponding force $\mathrm{F}_{\mathrm{p}}$. It should be noted that this force was decomposed into $\mathrm{x}$ and $\mathrm{y}$ axes components, instead along the lever axis, due to ABAQUS requirements. Hence, the values of this load were -269034 ( $\mathrm{x}$ axis) and $143048 \mathrm{~N}$ (y axis). To avoid confusion with the results, all forces were defined in Newtons and dimensions were assumed to be in milimeters, so that the stress results would be obtained in $\mathrm{N} / \mathrm{mm}^{2}$, i.e. in $\mathrm{MPa}$. Another load was defined at the bottom part of the lever, and it was equal to one quarter of the work load (since only one lever was modelled). Hence it was equal to -85837.5 N. Model geometry and loads can be seen in Fig. 5a. Boundary conditions were defined in the central opening, by constraining its inner surface. All displacements and rotations were prevented, with the exception of rotation about the $z$ axis, in order to replicate the real boundary conditions as close as possible. There is also a possibility to further improve this boundary condition, but this will be done in the future, once new and more complex models are developed. The boundary condition can be seen in Fig. 5 b.

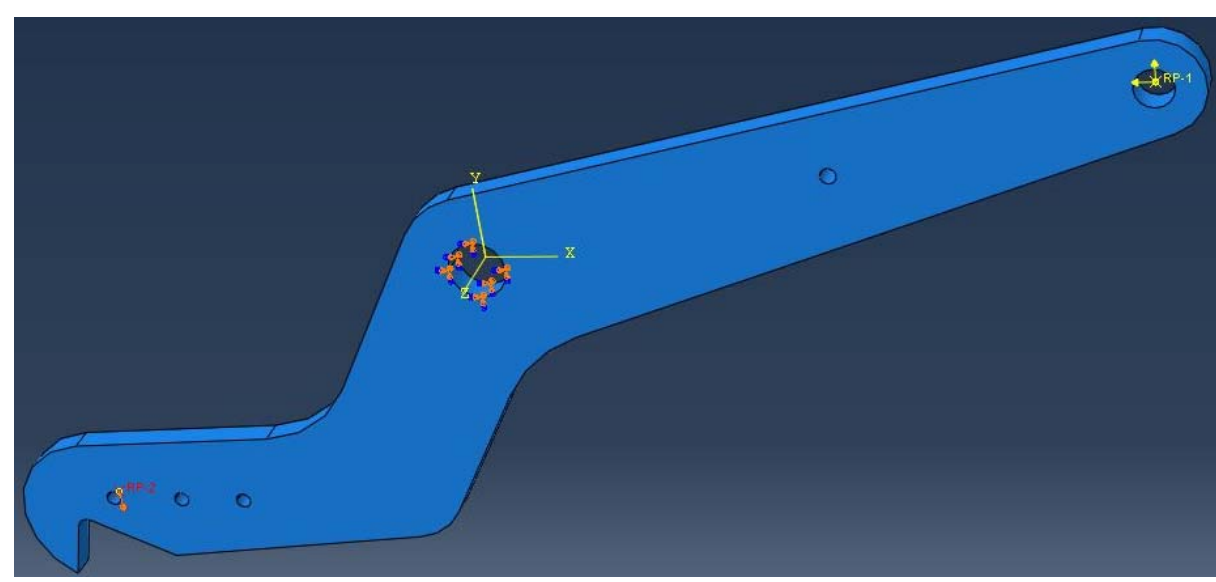

(a)

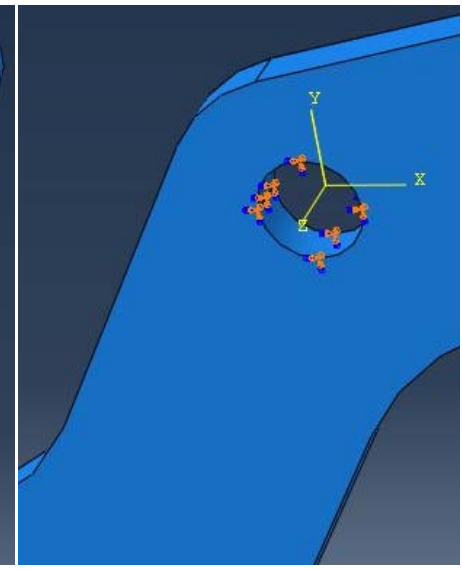

(b)

Figure 5: a) Numerical model geometry and loads (defined in RP-1 and RP-2 points b) The boundary condition (only the rotation about the $\mathrm{z}$-axis is allowed. 
Finally, the finite element mesh is given in Fig. 6. Element size was approximately $13.5 \mathrm{~mm}$, since it was determined that this size provides sufficient convergence of results, after a number of iterations. Element type used for this analysis was C3D8R, and the total number of elements and nodes was 30285 and 38330, respectively.

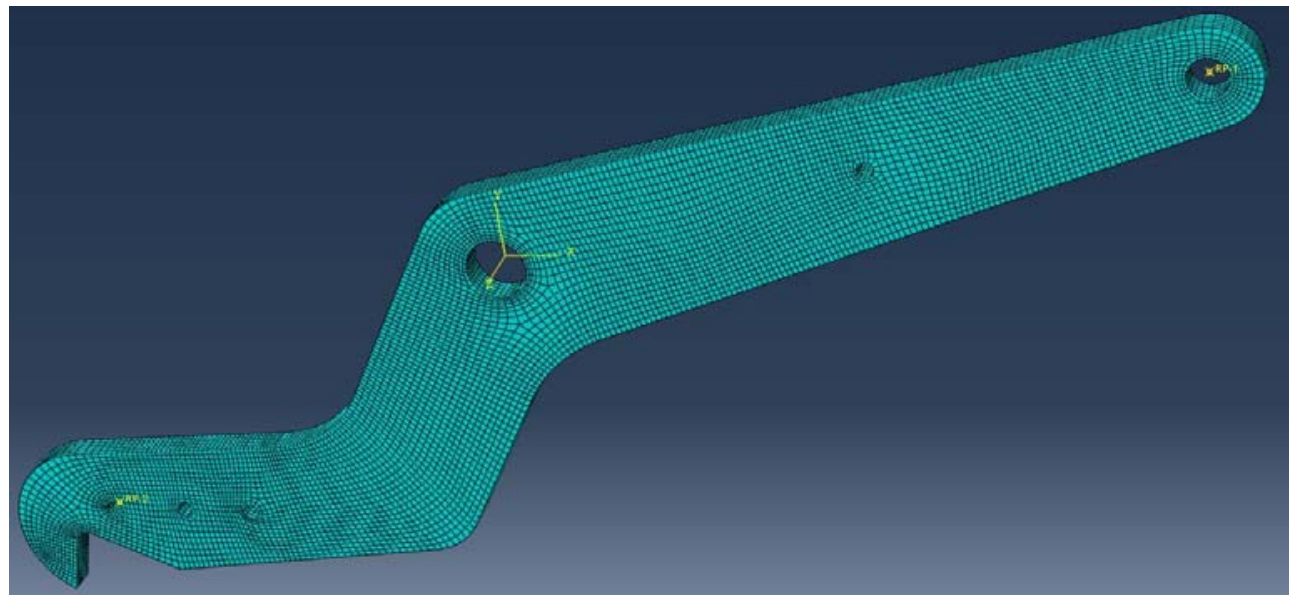

Figure 6: Finite element mesh of the model.
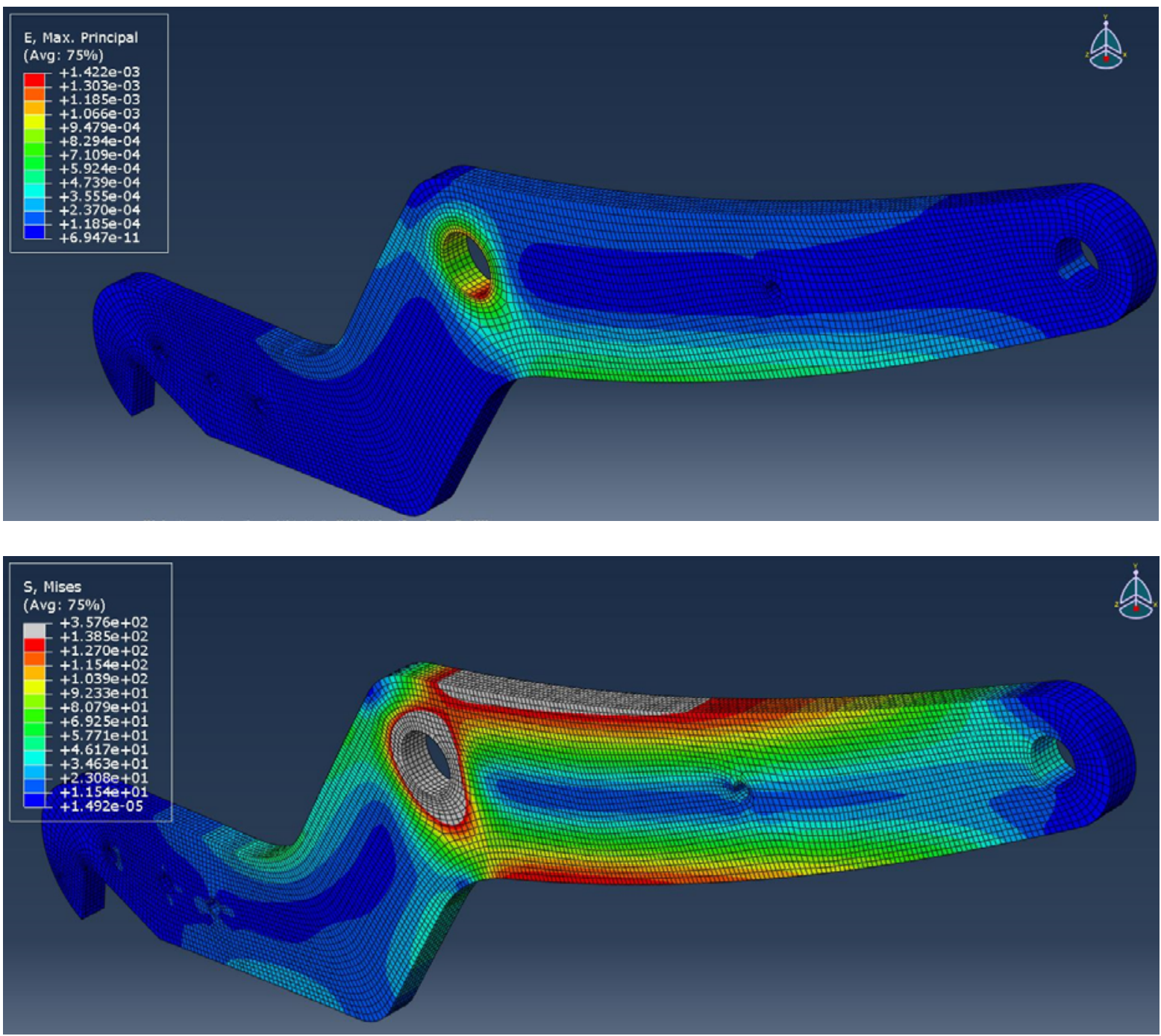

Figure 7: Strain (top) and stress (bottom) distribution in the numerical model. 
The results, including stress and strain magnitudes and distribution, are shown in Fig. 7 below. As can be seen, there are some very high stress values obtained in certain locations, which suggests that a more detailed approach is necessary in order to make a fully functional model. However, the goal of this initial version was to determine the location of the maximum tensile stresses, which is denoted by the red colour in the aforementioned figure. The areas with much higher stresses (grey) can be neglected in this case since they are:

- In the support, which is a commonly encountered case in static numerical simulations, and can be ignored.

- In the upper zone of the lever, where compressive stresses are dominant. Since these stresses have no influence on crack initiation, they were also not relevant.

Strain distribution indicated that the most deformed part, outside of the support, was the region where highest tensile stresses, with a magnitude of $138.5 \mathrm{MPa}$, had occurred. If this is compared to the real situation, it can be seen that there is good agreement between the locations of highest tensile loads, i.e. the potential crack in the model would be initiated near the location where the actual support lever broke. The stress value in this case is still considerably below the allowed stress, although it is over $50 \%$ higher than the analytical, which also confirms that the model needs to be improved.

\section{CONCLUSION}

$\mathrm{F}$ ailure of the slab carrying clamp support lever had occurred in the heat affected zone of the welded joint. It can be concluded and repeated from the introduction that welding had its influence, more accurately, lever failure was likely caused by inadequate preheating (taking into account the $70 \mathrm{~mm}$ thickness of the welded joint), which contributed to the forming of cold cracks specific for ferritic base material. This lead to a significant decrease in the toughness of the welded joint, which made it more vulnerable to calculated exploitation conditions. Performed and presented analytical calculation shows that highest stresses were indeed in the part of the lever where failure had occurred. The second lever failed in an identical manner, since it could not carry the load for both ones, it is simple remark that is not questionable. The following fact about structures like these is well-known: lever used as a load-bearing element should not have been welded and exposed to a high temperature. Non-uniform chemical composition of lever has its influence and indicates that allowed stress in analytical calculation has a different, lower, value. Exposing to high temperature may have had an influence on grain size of the lever microstructure as well, which can lead to a brittle and unpredictable fracture.

Numerical simulation of the behavior of the lever under the load also indicated that the highest tensile stresses, which are responsible for crack initiation, were at the location corresponding to the real failure location. However, this model was made with numerous approximations, and in order to obtain more accurate results in terms of stress distribution and magnitudes, it will need to be further developed. This includes the making of a more complex model, which would include more carrying clamp elements, and slightly different boundary conditions. Once the comparison between these models is made, the relevant one will be adopted as the base for analyzing the behavior of this structure in the presence of a crack in the heat affected zone.

\section{ACKNOWLEDGEMENT}

he authors of this paper acknowledge the support from Serbian Ministry of Education, Science and Technological Development Contract no. 451-03-68/2020-14/200135 and 451-03-68/2020-14/ 200213.

\section{REFERENCES}

[1] Đurđević, Đ., Anđelić, N., Milošević-Mitić, V., Maneski, T., Rakin, M., Đurđević, A. (2019). Influence of Encastering on Thin-Walled Cantilever Beams With U and Z Profiles on the Magnitude of Equivalent Stress and Deformation, Structural Integritya and Life, 19(3), EISSN 1820-7863, pp. 251-254 .

[2] Akbari, J., Salami, O., Isari, M. (2020). Numerical Investigation of the SeismicBehavior of Unanchored Steel Tanks with an emphasis on the Uplift Phenomenon, Frattura ed Integrità Strutturale, 53, pp. 92-105.

DOI: 10.3221/IGF-ESIS.53.08. 
[3] Sobrinho, B., Gomes, G., V. Silva, W., Silva, R., Bezerra, L, Palechor, E (2020). Differential Evolution Algorithm for Identification of Structural Damage in Steel Beams, Frattura ed Integrità Strutturale, 52, pp. 51-66.

DOI: 10.3221/IGF-ESIS.52.05.

[4] Gašić V., Arsić, A., Flajs, Ž. (2019). Experimental Study on the Stresses at the I-Beam End-Plate Moment Connection, Structural Integritya and Life, 19(1), pp. 53-57.

[5] Milovanović, N., Sedmak, A., Arsic, M., Sedmak, S. A., \& Božić, Ž. (2020). Structural integrity and life assessment of rotating equipment, Engineering Failure Analysis, 104561. DOI: 10.1016/j.engfailanal.2020.104561.

[6] Jeremić, L., Sedmak, A., Petrovski, B., Đorđević, B., Sedmak, S. (2020). Structural Integrity Assessment of Welded Pipeline Designed with Reduced Safety, Technical Gazzete, 27(5), pp. 1461-1466.

DOI: $10.17559 /$ TV-20200413142538.

[7] Medjo, B. Arsić, M., Mladenović, M., Savić, Z., Grabulov, V., Radosavljević, Z., Rakin, M. (2020). Influence of Defects on Limit Loads and Integrity of the Pipeline at Hydropower Plant 'Pirot', Structural Integrity and Life, 20(1), pp. 8286

[8] Martić, I., Sedmak, A., Mitrović, N., Sedmak, S., Vučetić, I. (2019). Effect of Over-Pressure on Pipeline Structural Integrity, Technical Gazzete, 26(3), pp. 852-855. DOI: 10.17559/TV-20180708213323

[9] Tanasković, D., Tatić, U., Đorđević, B., Sedmak, S., Sedmak, A. (2017). The Effect of Cracks on Stress State in Crane Wheel Hard-surface Under Contact Loading, Technical Gazzete, 24(Supplement 1), pp. 169-175. DOI: $10.17559 /$ TV-20151227221434.

[10] Molaei, S., Attarian, M., Kermajani, M., Jahromi, S. K. G., Alemi, M. (2019). Failure Analysis of a Damaged Drilling Stabilizer, Engineering Failure Analysis 103, pp. 517-529. DOI: 10.1016/j.engfailanal.2019.05.014.

[11] Kirin, S., Jeremić, L., Sedmak, A., Martić, I., Sedmak, S., Vučetić, I., Golubović, T. (2020). Risk Based Analysis of RHPP Penstock Structural Integrity, Frattura ed Integrità Strutturale, 2020, 14(53), pp. 345-352. DOI: 10.3221/IGF-ESIS.53.27.

[12] Zaidi, R., Sedmak, A., Kirin, S., Grbovic, A., Li, W., Lazic Vulicevic, L., Sarkocevic, Z. (2020). Risk Assessment of Oil Drilling Rig Welded Pipe Based on Structural Integrity and Life Estimation, Engineering Failure Analysis 112, 104508. DOI: 10.1016/j.engfailanal.2020.104508.

[13] Milovanović, N., Đorđević, B., Tatić, U., Sedmak, S.A., Štrbački, S. (2017). Low-Temperature Corrosion Damage and Repair of Boiler Bottom Panel Tubes, Struuctural Integrity and Life, 17(2), pp. 125-131.

[14] Wang, K., Tan, Z., Cheng, C., Gao, B., Gao, G., Misra, R. . K., \& Bai, B. (2016). Effect of Microstructure on the Spalling Damage in a 20Mn2SiCrMo Bainitic Fail, Engineering Failure Analysis, 70, pp. 343-350.

DOI: 10.1016/j.engfailanal.2016.09.011.

[15] Bieniaś, J., Dębski, H., Surowska, B., Sadowski, T. (2012). Analysis of Microstructure Damage in Carbon/Epoxy Composites using FEM, Computational Materials Science, 64, pp. 168-172. DOI: 10.1016/j.commatsci.2012.03.033.

[16] Džindo, E., Sedmak, S.A., Grbović, A., Milovanović, N., Đođrević, B. (2019). XFEM Simulation of Fatigue Crack Growth in a Welded Joint of a Pressure Vessel with a Reinforcement Ring, Archive of Applied Mechanics, 89(5), pp. 919-926, DOI: 10.1007/s00419-018-1435-1.

[17] Total Materia - http://www.totalmateria.com

[18] Elektrode Jesenice catalogue - Additional materials for welding (https://sij.elektrode.si)

[19] Beer, F. P., Johnston Jr, E. R., DeWolf, J. T., Mazurek, D. F. (2012). Mechanics of Materials (6 $6^{\text {th }}$ edition), McGraw Hill, ISBN 978-0-07-338028-5.

[20] Meriam, J. L., Kraige, L G. (2012). Engineering Mechanics - Statocs (7th edition), John Wiley \& Sons, Inc., ISBN: 9780-470-61473-0.

[21] Golubović, Z., Simonović, M., Mitrović, Z. (2007). Mehanika - Statika, Mašinski fakultet Univerziteta u Beogradu, Beograd. 